\title{
Radiative budget and cloud radiative effect over the Atlantic from ship-based observations
}

\author{
J. Kalisch ${ }^{1,2}$ and A. Macke ${ }^{2}$ \\ ${ }^{1}$ Helmholtz Centre for Ocean Research Kiel (GEOMAR), Duesternbrooker Weg 20, 24105 Kiel, Germany \\ ${ }^{2}$ Leibniz-Institute for Tropospheric Research (IfT), Permoserstraße 15, 04318 Leipzig, Germany \\ Correspondence to: J. Kalisch (kalisch@tropos.de)
}

Received: 18 January 2012 - Published in Atmos. Meas. Tech. Discuss.: 1 March 2012

Revised: 23 August 2012 - Accepted: 5 September 2012 - Published: 16 October 2012

\begin{abstract}
The aim of this study is to determine cloud-type resolved cloud radiative budgets and cloud radiative effects from surface measurements of broadband radiative fluxes over the Atlantic Ocean. Furthermore, based on simultaneous observations of the state of the cloudy atmosphere, a radiative closure study has been performed by means of the ECHAM5 single column model in order to identify the model's ability to realistically reproduce the effects of clouds on the climate system.
\end{abstract}

An extensive database of radiative and atmospheric measurements has been established along five meridional cruises of the German research icebreaker Polarstern. Besides pyranometer and pyrgeometer for downward broadband solar and thermal radiative fluxes, a sky imager and a microwave radiometer have been utilized to determine cloud fraction and cloud type on the one hand and temperature and humidity profiles as well as liquid water path for warm nonprecipitating clouds on the other hand.

Averaged over all cruise tracks, we obtain a total net (solar + thermal) radiative flux of $144 \mathrm{~W} \mathrm{~m}^{-2}$ that is dominated by the solar component. In general, the solar contribution is large for cirrus clouds and small for stratus clouds. No significant meridional dependencies were found for the surface radiation budgets and cloud effects. The strongest surface longwave cloud effects were shown in the presence of low level clouds. Clouds with a high optical density induce strong negative solar radiative effects under high solar altitudes. The mean surface net cloud radiative effect is $-33 \mathrm{~W} \mathrm{~m}^{-2}$.

For the purpose of quickly estimating the mean surface longwave, shortwave and net cloud effects in moderate, subtropical and tropical climate regimes, a new parameterisation was created, considering the total cloud amount and the solar zenith angle.
The ECHAM5 single column model provides a surface net cloud effect that is more cooling by $17 \mathrm{~W} \mathrm{~m}^{-2}$ compared to the radiation observations. This overestimation in solar cooling is mostly caused by the shortwave impact of convective clouds. The latter show a large overestimation in solar cooling of up to $114 \mathrm{~W} \mathrm{~m}^{-2}$. Mean cloud radiative effects of cirrus and stratus clouds were simulated close to the observations.

\section{Introduction}

Shortwave (SW) and longwave (LW) radiation are the main components of the Earth's energy budget. The total net radiative flux (radiative budget) is defined as the sum of downward SW radiation (DSR, $F_{\mathrm{DSR}}$ ), downward LW radiation (DLR, $\left.F_{\mathrm{DLR}}\right)$, outgoing SW radiation (OSR, $\left.F_{\mathrm{OSR}}\right)$ and outgoing LW radiation (OLR, $\left.F_{\mathrm{OLR}}\right)$. DSR, DLR and OSR are strongly influenced by clouds.

Clouds cause opposing SW and LW effects. The SW scattering and absorption by clouds depend on the solar zenith angle, the cloud cover, the cloud type, the condition of aggregation of the cloud particles as well as the cloud shape, vertical extension and optical density generally causing a surface shading. Only broken clouds can lead to occasional, strong, short-term enhancements of the surface DSR (Schade et al., 2007). In the LW spectra, clouds absorb the surface OLR and re-emit DLR that contributes to the total greenhouse effect.

The occurrence of clouds shows a large spatial and temporal variability owing to convective and turbulent cloud physical processes. This leads to a large variability of the DSR and the DLR at the surface. 
The total net radiative flux is the sum of SW and LW fluxes, whereupon downward radiative fluxes are defined with positive and upward with negative sign. A positive budget at the surface leads to a heating of the ground. The computation of the Earth's radiation budget at the surface and at the top of atmosphere is mostly performed by taking into account both the satellite and model data (Rossow and Zhang, 1995; Zhang et al., 2004; Trenberth et al., 2009).

The cloud radiative effect (CRE) is calculated as the difference of the all sky net radiative flux and a comparable clear sky atmosphere net radiative flux. In the present study, clear sky radiative properties are based on parameterisations. On a global scale clouds have a surface cooling effect (Ramanathan et al., 1989; Kiehl and Trenberth, 1997; Greenwald et al., 2010).

As a matter of fact, in-situ measurements of radiation are point measurements. But in contrast to e.g. satellite data, insitu measurements provide a very high temporal resolution and an excellent accuracy. Fast fluctuating radiative fluxes play a major role for biological and chemical processes (Marra, 1978; Walsh and Legendre, 1983). A few radiation measurements were used to study the surface radiation budget and the CRE. For example, from ship- and buoy-based measurements, Fairall et al. (2008) estimated a surface CRE in the tropical Pacific of $-40 \mathrm{~W} \mathrm{~m}^{-2}$. Dupont and Haeffelin (2008) found a cirrus CRE at the surface of $-50 \mathrm{~W} \mathrm{~m}^{-2}$ in the SW and of $+5 \mathrm{~W} \mathrm{~m}^{-2}$ in the LW. Detailed radiative characteristics for the north of Germany have been presented by Kasten and Czeplak (1980). They have shown the ratio of the irradiance under cloudy to that under clear sky with regard to solar elevation and cloud type, which may be interpreted as the transmittance in case of overcast conditions.

The Atmospheric Radiation Measurement (ARM) Program has put emphasis on the investigation of clouds, aerosols and its impact on radiative properties in our climate system. Slingo et al. (2009) have combined surface (ARM) and satellite measurements to determine the impact of aerosol, temperature profile and integrated water vapour onto the SW and LW radiative transfer. Miller et al. (2009) have shown that the energy budget is dominated by the LW fluxes (sensible heat) in dry season and by fluxes of latent heat in rainy season. The radiation effect of aerosols and dust events has been quantified by Bharmal et al. (2009) and was found to exceed $-20 \mathrm{~W} \mathrm{~m}^{-2}$ regularly.

In this study we present the surface net radiative fluxes and radiative effects by clouds as a result of several meridional research cruises onboard the research vessel (RV) Polarstern. Special emphasis is given to distinguish between different cloud types. The measurements were continuously performed along the moderate, subtropical and tropical climate zones from $54^{\circ} \mathrm{N}$ to $43^{\circ} \mathrm{S}$ (Sect. 2). Details of the automated detection of the cloud cover and the cloud type are given in Sect. 3. Calculations of the net radiative fluxes and CREs are performed for all sky conditions and based on the cloud type (Sect. 4). The conclusions are given in Sect. 5.

\section{Meridional radiative flux determination}

This study is based on the data acquisition performed on five expedition cruises of RV Polarstern that is operated by the Alfred Wegener Institute for Polar and Marine Research. The vessel generally crosses the Atlantic Ocean in spring and autumn, enabling continuous measurements of radiative fluxes and cloud properties in several climate zones. Figure 1 shows the cruise tracks of the expedition legs ANT-XXIII/10, ANTXXIV/1, ANT-XXIV/4, ANT-XXV/5 and ANT-XXVI/1.

Table 1 lists the dates of each cruise leg and the corresponding cruise reports. Apart from standard meteorological observations, radiometric (Sect. 2.1) and sky imager measurements (Sect. 3) as well as a high-frequency remote sensing of the atmosphere were performed. For the latter a passive microwave radiometer determines vertical profiles of temperature and humidity as well as the integrated water vapour (IWV) and the liquid water path (LWP) (Rose et al., 2005). Finally, daily launched radio soundings provide the atmospheric in-situ temperature and humidity.

\subsection{All sky radiation measurements}

The DSR has been recorded by means of the pyranometer Kipp \& Zonen CM21. The spectral range covers $305 \mathrm{~nm}$ to $2800 \mathrm{~nm}$. Maximal errors of $2 \%$ are expected for daily sums (Kipp \& Zonen, 2004). The movement of the vessel and its superstructure might cause errors. However, a comparison with the ships onboard SW measurements has shown neither significant systematic under- nor overestimation.

The DLR was measured by the pyrgeometer Kipp \& Zonen CG4 within the range from $4.5 \mu \mathrm{m}$ to $42 \mu \mathrm{m}$. According to Kipp \& Zonen (2001), maximal errors of $3 \%$ are expected for daily sums. The radiation data are sampled with $1 \mathrm{~Hz}$. In the following analysis, 10-min averages of radiation measurements were applied. Further descriptions of the standard meteorological and radiative measurements onboard RV Polarstern can be found in König-Langlo et al. (2006) and Macke et al. (2010a,b).

\subsection{Clear sky radiation estimates}

The estimation of DSR and DLR under clear sky conditions is essential for determining the CREs. While all-sky downward radiative fluxes are measured directly, clear sky fluxes have to be parameterised with the use of surface meteorological measurements.

In the following work, the parameterisation by Zillman (1972) modified by Kalisch and Macke (2008) for clear sky conditions was used. The surface clear sky insolation $F_{\text {DSR_clr }}$ can be derived (in $\mathrm{W} \mathrm{m}^{-2}$ ) from

$F_{\text {DSR_clr }}=S_{0} \cdot \cos \theta \cdot \tau$

with the solar constant $S_{0}$ in $\mathrm{W} \mathrm{m}^{-2}$, the solar zenith angle $\theta$ and the transmission coefficient $\tau$. The transmission for clear skies follows the empirical formula: 


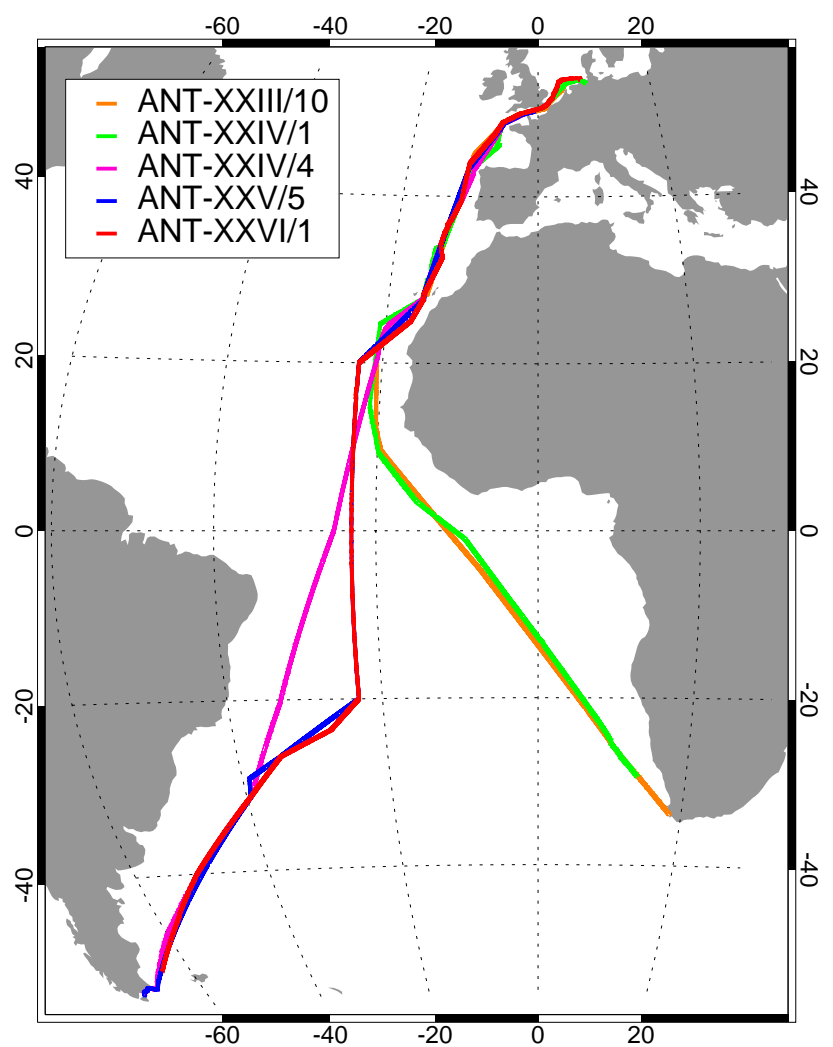

Fig. 1. Transatlantic cruise tracks of RV Polarstern at the expedition legs ANT-XXIII/10, ANT-XXIV/1, ANT-XXIV/4, ANT$\mathrm{XXV} / 5$ and ANT-XXVI/1.

$\tau=\frac{\cos \theta}{(\cos \theta+1.50) p_{\mathrm{w}} 10^{-3}+1.14 \cos \theta+0.08}$

with the partial pressure of water vapour $p_{\mathrm{w}}$ in $\mathrm{hPa}$ at the surface. This modified transmission equation was the result of analysing two datasets of transatlantic radiation measurements. The impact of the mean maritime background aerosol on the atmospheric transmission was taken into account. Outstanding aerosol concentrations (e.g. due to Saharan dust events) cause significantly higher aerosol optical densities, which are not considered in the parameterisation.

In agreement with studies of Kopp et al. (2005), Lean et al. (2005), Rottman (2006) and Kopp and Lean (2011), a solar constant of $1362 \mathrm{~W} \mathrm{~m}^{-2}$ was assumed.

The DLR varies between $200 \mathrm{~W} \mathrm{~m}^{-2}$ and $450 \mathrm{~W} \mathrm{~m}^{-2}$ mainly depending on cloud properties and air temperature. Jiménez et al. (1987) discussed several parameterisations based on simple empirical and analytical methods for estimating clear sky DLR that have been tested on the transatlantic ANT-XXIV/4 and ANT-XXIV/4 datasets. The best results were achieved by the Idso and Jackson (1969) parameterisation taking into account both a small mean error $(-1.0 \%)$ and a low RMSE $(4.5 \%)$. With the air temperature
Table 1. Cruise legs of RV Polarstern and its expedition reports.

\begin{tabular}{lcl}
\hline Cruise leg & \multicolumn{1}{c}{ Date } & Expedition report \\
\hline ANT-XXIII/10 & 12 Apr-4 May 2007 & Macke (2008) \\
ANT-XXIV/1 & 26 Oct-26 Nov 2007 & Schiel (2009) \\
ANT-XXIV/4 & 18 Apr-20 May 2008 & Macke (2009) \\
ANT-XXV/5 & 11 Apr-24 May 2009 & Zenk and El Naggar (2010) \\
ANT-XXVI/1 & 16 Oct-25 Nov 2009 & El Naggar and Macke (2010) \\
\hline
\end{tabular}

$T$ in $\mathrm{K}$ measured operationally at a height of $35 \mathrm{~m}$ and the constant $d=7.77 \times 10^{-4} \mathrm{~K}^{-2}$, the parameterised clear sky DLR $F_{\text {DLR_clr }}$ in $\mathrm{W} \mathrm{m}^{-2}$ follows from

$F_{\text {DLR_clr }}=\sigma T^{4}\left(1-0.261 \exp \left(-d(273-T)^{2}\right)\right)$.

\section{Cloud detection}

A full sky imager developed at the Leibniz Institute of Marine Science at the University of Kiel (IFM-GEOMAR) (Kalisch and Macke, 2008) was used on all research cruises for continuous sky observations. The main component is a commercially available digital CCD camera equipped with a fisheye lens to realise a field of view of $183^{\circ}$. The images are stored in JPEG format with $2272 \times 1704$ pixel spatial resolution and a sampling rate of $15 \mathrm{~s}$. In the following analysis, 10-min averages of detected cloud measurements were applied.

Retrievals to derive the total cloud amount and the type of clouds from sky images are initially based on synoptic observations or visual inspection of the images. Thus, a single cloud detection cannot be of higher quality than the synoptic observation. But sky imagery allows for an automated operational use with high temporal resolution. Its results and errors are persistent and reproducible. The image archive enables visual inspection of single events or time lapse animations.

When comparing synoptical data with sky imagery results, one has to consider that meteorological observations contain various biases (Kent et al., 1993; Kent and Berry, 2005). Pallé and Butler (2002) even found a significant personal bias in synoptic data linked to single observers which makes a scientific analysis of, for example, trends impossible.

\subsection{Cloud cover}

The distribution of cloudy and clear sky pixels on the image is calculated from the red versus blue threshold criteria given by Long and DeLuisi (1998). According to Kalisch and Macke (2008), the optimal empirical threshold for the applied CCD camera was set to 0.8. The total amount of clouds results from the ratio of cloudy pixels and total pixels, where the ship's superstructure has been masked out. Pixels of the direct sun appear almost white and are misinterpreted as cloudy. To correct for such errors, direct sun situations have been identified from light dispersion on the acrylic glass 
dome, and the calculated cloud amount was reduced by $9 \%$ (Kalisch and Macke, 2008). No cosine-weighting of horizontal near pixel has been performed in order to minimize the influence of cloud sides on the total cloud cover (Schade et al., 2007).

From our synoptic cloud observations, we find that $50 \%$ of the images show a difference between calculated and observed total cloud cover of no more that $10 \%$. This coincides with the accuracy for sky imagery given by Feister and Shields (2005). Largest errors of up to $50 \%$ occur during clear sky sunrise and sunset due to an enhanced atmospheric spectral scattering. For overcast conditions the retrieval is very robust.

\subsection{Cloud type}

The automated classification of clouds by means of sky imagery was performed using the pattern recognition algorithm by Heinle et al. (2010). Seven cloud classes can be distinguished:

$$
\begin{aligned}
& 1=\text { Cumulus }(\mathrm{Cu}) ; \\
& 2=\text { Cirrus }(\mathrm{Ci}), \text { Cirrostratus }(\mathrm{Cs}) ; \\
& 3 \text { = Cirrocumulus }(\mathrm{Cc}), \text { Altocumulus (Ac); } \\
& 4=\text { Clear sky; } \\
& 5=\text { Stratocumulus }(\mathrm{Sc}) ; \\
& 6=\text { Stratus (St), Altostratus (As); } \\
& 7=\text { Cumulonimbus }(\mathrm{Cb}), \text { Nimbostratus }(\mathrm{Ns}) .
\end{aligned}
$$

The algorithm is based on the $k$-nearest-neighbour $(\mathrm{kNN})$ method by Duda and Hart (2001). A training set of selected images for each of the cloud classes was used to define 12 normalised feature vectors in order to characterise spectral and textural features of the image. To classify an unknown image, its feature vectors are compared with the typical vectors of the training data and the kNN classifier votes for the one with the smallest absolute distance.

Heinle et al. (2010) give an accuracy of $97 \%$ for the leaveone-out cross-validation. For the classification of random images, a success rate of $75 \%$ has been found. Thin cirrus, rain drops on the imager dome and the coexistent presence of several cloud types can lead to misidentifications.

\section{Results}

\subsection{Net radiative flux calculations}

The net radiative flux is defined as downward minus upward absolute fluxes. For the surface total net radiative flux, $F 0_{\text {BUD_net }}$ follows

$F_{\mathrm{BUD} \text { net }}=F_{\mathrm{DSR}}+F_{\mathrm{DLR}}-F_{\mathrm{OSR}}-F_{\mathrm{OLR}}$.
The DSR and DLR have been measured using radiometers. The upward OSR was calculated from the insolation multiplied by the ocean surface albedo according to Fresnel's law. A typical fraction of the albedo due to the backscattering within the ocean water is $1.56 \%$ (Eucken, 1952). Following Dera (1992) the albedo $\alpha$ is defined as

$\alpha=\frac{1}{2}\left(\frac{\sin ^{2}(\theta-\xi)}{\sin ^{2}(\theta+\xi)}+\frac{\tan ^{2}(\theta-\xi)}{\tan ^{2}(\theta+\xi)}\right)+0.0156$,

with the solar zenith angle $\theta$ and the refraction angle by the Snell's law $\xi$.

In this study the impact of the sea surface roughness is neglected. Jin et al. (2002) show that the impact of the wind speed on the albedo of the sea surface is minor. Only at low solar elevations, when SW fluxes are small, there is a significant dependency of the albedo on wind speed and roughness. Li et al. (2006) found that the surface global energy balance of a climate model is surprisingly insensitive to the OSR scheme.

The upward OLR was calculated using the StefanBoltzmann law. The temperature of the emitting uppermost layer of the sea surface (skin temperature) has not been measured. Instead the SST determined operationally in $5 \mathrm{~m}$ depth was used for the estimation of the OLR. According to Schluessel et al. (1990), a mean difference between skin temperature and SST of $0.1 \mathrm{~K}$ to $0.2 \mathrm{~K}$ can be expected.

Figure 2 shows the surface net radiative flux along the Polarstern cruises ANT-XXIII/10, ANT-XXIV/1, ANTXXIV/4, ANT-XXV/5 and ANT-XXVI/1 as a function of latitude from south (negative latitudes) to north (positive latitudes). Nighttime measurements are illustrated in dark green. Mean and standard deviation of the surface LW, SW and net radiative fluxes are given in Table 2 for the entire dataset and for daytime-only cloud classes. The calculated radiative fluxes cannot be transferred onto different meridional or global extents.

There is no obvious meridional dependency of the net radiative flux within the present latitudinal extent. The negative LW flux mostly depends on cloud cover and cloud base height. The positive SW flux depends on solar zenith angle, cloud cover and cloud type and dominates daily net radiative sums. Thus, smaller flux values south of $35^{\circ} \mathrm{S}$ and north of $45^{\circ} \mathrm{N}$ are consistent with the smaller solar budget at higher latitudes. However, the data were recorded with lower data density and therefore have a weaker climatological significance. In addition, the ship tracks do not sufficiently extend into the mid-latitudes to show a clear meridional variability. Furthermore, meridional changes in cloud cover and cloud bottom height may dominate over the purely astronomical conditions.

Due to the limitation of the cloud type classification to daytime, the radiative fluxes for separate cloud classes were calculated for daytime measurements only. The mean nighttime LW flux for separate cloud classes is expected to be 


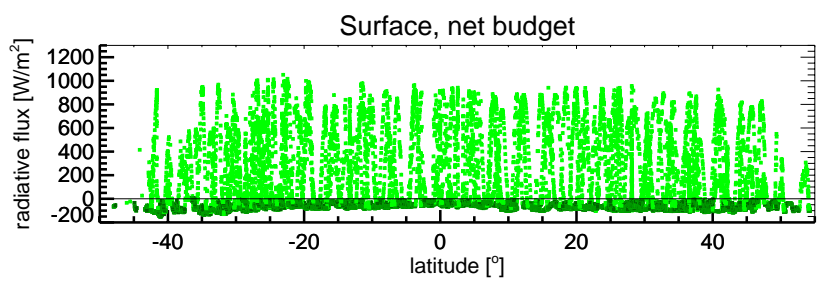

Fig. 2. Surface net radiative flux on the basis of ANT-XXIII/10, ANT-XXIV/1, ANT-XXIV/4, ANT-XXV/5 and ANT-XXVI/1. Dark green symbols illustrate nighttime measurements.

slightly different from daytime values due to the small diurnal cycle of the maritime temperatures (Webster et al., 1996). Of course, the SW flux is zero at night. In the LW range, cirrus and broken cumulus clouds lead to a small thermal back radiation and therefore yield a large negative surface flux similar to the clear-sky conditions. The mean clear sky SW flux of $183 \mathrm{~W} \mathrm{~m}^{-2}$ seems to be in contradiction with much higher mean radiative flux for cloudy scenarios. However, in agreement with studies of Sui et al. (1997), we found a strong diurnal frequency of occurrence in tropical clear sky events: at local noontime, cloud-free events were very rare, which strongly reduces the effective clear sky SW flux. Cirrocumulus and altocumulus had a maximum frequency of occurrence around noon, cumulus a minimum.

\subsection{Cloud radiative effect}

The net CRE is the difference of the all sky net radiative flux and the parameterised clear sky net radiative flux (see Sect. 2.2). The calculation of the net cloud radiative effect $F_{\text {CRE_net follows: }}$

$$
\begin{aligned}
F_{\text {CRE_net }} & =F_{\mathrm{DSR}}+F_{\mathrm{DLR}}-F_{\mathrm{OSR}} \\
& -\left(F_{\mathrm{DSR} \_c l r}+F_{\text {DLR_clr }}-F_{\text {OSR_clr }}\right) .
\end{aligned}
$$

The $F_{\text {OSR_clr }}$ has been calculated by multiplying the $F_{\text {DSR_clr }}$ with the surface albedo $\alpha$ (Eq. 5). The OLR is invariant to the cloud cover and cancels out.

In general clouds have a surface SW cooling effect (negative SW CRE), although radiation enhancements due to the broken cloud effect can even lead to occasional and local larger fluxes at the surface than at the top of atmosphere (see Schade et al., 2007). Therefore, on short time-scales convective clouds can have a positive CRE. The surface LW CRE is positive (warming effect) due the fact that the atmospheric back radiation for clear skies is always smaller than that of cloudy sky. Higher-altitude cloud types are expected to show smaller LW CREs. For the following calculation of CREs, outstanding Saharan dust events were excluded from the dataset, because the parameterisation given in Eq. (2) was created for mean Atlantic background aerosol effects only. The measurements from 22-23 April 2007 (ANT-XXIII/10), 7-9 November 2007 (ANT-XXIV/1), 5-8 May 2008 (ANTXXIV/4), 6-9 May 2009 (ANT-XXV/5) and 31 October-

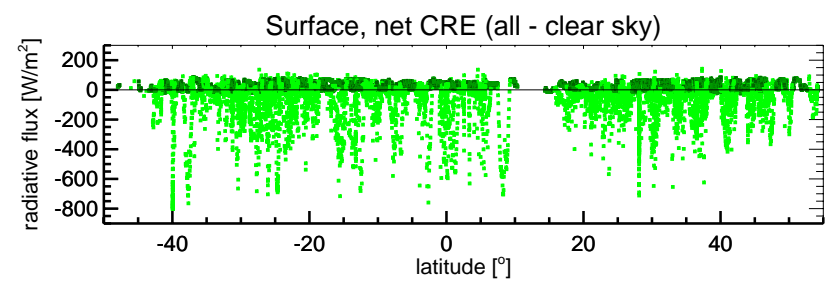

Fig. 3. Surface net cloud radiative effect during Polarstern expeditions ANT-XXIII/10, ANT-XXIV/1, ANT-XXIV/4, ANT-XXV/5 and ANT-XXVI/1. Dark green symbols illustrate nighttime observations.

1 November 2009 (ANT-XXVI/1) have not been taken into account.

Figure 3 shows the surface net cloud radiative effect along the Polarstern cruises ANT-XXIII/10, ANT-XXIV/1, ANTXXIV/4, ANT-XXV/5 and ANT-XXVI/1. Dark green symbols illustrate nighttime observations when the SW CRE is zero. The mean and standard deviation of the LW, SW and net surface CREs are given in Table 3 for the entire dataset and daytime-separated cloud classes.

The LW CRE shows no diurnal or meridional dependency. It varies between $-40 \mathrm{~W} \mathrm{~m}^{-2}$ and $100 \mathrm{~W} \mathrm{~m}^{-2}$. The negative values are assumed to originate from measurement and parameterisation errors. The SW CRE is dominated by the diurnal solar cycle and varies between $-900 \mathrm{~W} \mathrm{~m}^{-2}$ and $100 \mathrm{~W} \mathrm{~m}^{-2}$. Highest negative effects are caused by optically thick clouds and high solar elevations. At nighttime or under clear sky conditions, the SW CRE is zero. Positive SW CREs result from radiative enhancements during broken cloud events. However, measurement and parameterisation errors may contribute. Due to the meridional dependency of the solar zenith angle, the SW CRE varies with the latitude in general. However, due to the small amount of data at higher latitudes, the effect is not significant.

The CREs for the cloud type class 4 (clear sky) are supposed to amount to zero. The nonzero values resulting from our analysis (Table 3, class 4, upright font) were taken as a systematic bias error and were used as correction terms for the clear sky cases and all cloud classes. Note that the CREs for separate cloud classes were calculated for daytime measurements only. The correction terms for the entire dataset in the SW and net range have been weighted with the number of night and day measurements.

The LW and SW CRE are small for thin and broken clouds (class 1 and 2). Largest effects result from stratus clouds with a net CRE of $-269 \mathrm{~W} \mathrm{~m}^{-2}$. Optically thick cumulonimbus clouds (class 7) show a net CRE of $-114 \mathrm{~W} \mathrm{~m}^{-2}$ due to a minimum of occurrence during noon and due to frequently partial cloud covers. In case of cirrus clouds, the effect calculated by Dupont and Haeffelin (2008) with a SW CRE of $-50 \mathrm{~W} \mathrm{~m}^{-2}$ is not confirmed. One possible reason for this larger value may be the focus on overcast cirrus in their study, whereas our CRE includes all occurring cloud cover. 
Table 2. Surface LW, SW and net radiative flux mean $\overline{F_{\mathrm{BUD}}}$ and standard deviation $\sigma$ in $\mathrm{W} \mathrm{m}^{-2}$ for the entire dataset and cloud classes during daytime.

\begin{tabular}{|c|c|c|c|c|c|c|}
\hline \multicolumn{7}{|c|}{ Surface radiative flux } \\
\hline & $\overline{F_{\text {BUD_LW }}}$ & $\sigma_{\mathrm{LW}}$ & $\overline{F_{\text {BUD_SW }}}$ & $\sigma_{\mathrm{SW}}$ & $\overline{F_{\text {BUD_net }}}$ & $\sigma_{\text {net }}$ \\
\hline & \multicolumn{6}{|c|}{ All sky, full dataset } \\
\hline & -59.7 & 26.8 & 204.2 & 297.0 & 144.1 & 296.9 \\
\hline Class (cloud type) & \multicolumn{6}{|c|}{ Daylight measurements } \\
\hline $1(\mathrm{Cu})$ & -67.8 & 21.0 & 426.1 & 313.2 & 354.8 & 314.8 \\
\hline $2(\mathrm{Ci}, \mathrm{Cs})$ & -74.3 & 20.8 & 512.4 & 338.4 & 439.9 & 336.9 \\
\hline $3(\mathrm{Cc}, \mathrm{Ac})$ & -49.2 & 23.9 & 456.5 & 273.3 & 405.8 & 272.7 \\
\hline 4 (clear sky) & -81.2 & 22.8 & 262.3 & 227.8 & 183.2 & 226.3 \\
\hline $5(\mathrm{Sc})$ & -40.4 & 18.1 & 338.3 & 248.8 & 297.7 & 249.0 \\
\hline $6(\mathrm{St}, \mathrm{As})$ & -31.7 & 18.9 & 228.9 & 222.0 & 197.4 & 213.4 \\
\hline $7(\mathrm{Cb}, \mathrm{Ns})$ & -37.6 & 16.5 & 266.6 & 262.2 & 215.5 & 250.2 \\
\hline
\end{tabular}

Table 3. LW, SW and net surface cloud radiative effect mean $\overline{F_{\mathrm{CRE}}}$ and standard deviation $\sigma$ in $\mathrm{W} \mathrm{m}^{-2}$ for the entire dataset and cloud classes during daytime. Correction terms based on clear sky observations are given in italic font.

\begin{tabular}{|c|c|c|c|c|c|c|}
\hline \multicolumn{7}{|c|}{ Surface cloud radiative effect } \\
\hline & $\overline{F_{\text {CRE_LW }}}$ & $\sigma_{\mathrm{LW}}$ & $\overline{F_{\text {CRE_SW }}}$ & $\sigma_{\mathrm{SW}}$ & $\overline{F_{\text {CRE_net }}}$ & $\sigma_{\text {net }}$ \\
\hline & \multicolumn{6}{|c|}{ All sky, full dataset } \\
\hline & $25.0-4.6$ & 24.9 & $-61.4+8.1$ & 128.9 & $-36.2+3.4$ & 121.1 \\
\hline Class (cloud type) & \multicolumn{6}{|c|}{ Daylight measurements } \\
\hline $1(\mathrm{Cu})$ & $15.8-4.6$ & 15.7 & $-53.1+16.1$ & 78.9 & $-37.1+10.0$ & 76.2 \\
\hline $2(\mathrm{Ci}, \mathrm{Cs})$ & $9.4-4.6$ & 18.2 & $-30.5+16.1$ & 50.3 & $-21.1+10.0$ & 53.3 \\
\hline $3(\mathrm{Cc}, \mathrm{Ac})$ & $36.0-4.6$ & 22.6 & $-175.7+16.1$ & 168.6 & $-140.0+10.0$ & 155.5 \\
\hline 4 (clear sky) & $4.6-4.6$ & 19.2 & $-16.1+16.1$ & 37.9 & $-10.0+10.0$ & 41.5 \\
\hline $5(\mathrm{Sc})$ & $44.6-4.6$ & 16.1 & $-221.6+16.1$ & 144.2 & $-175.1+10.0$ & 138.4 \\
\hline $6(\mathrm{St}, \mathrm{As})$ & $57.4-4.6$ & 16.6 & $-336.0+16.1$ & 202.5 & $-278.8+10.0$ & 198.7 \\
\hline $7(\mathrm{Cb}, \mathrm{Ns})$ & $50.1-4.6$ & 15.6 & $-178.5+16.1$ & 162.8 & $-123.8+10.0$ & 157.0 \\
\hline
\end{tabular}

The cirrus effects by Chen et al. (2000) with a LW CRE of $8 \mathrm{~W} \mathrm{~m}^{-2}$ and a SW CRE of $-22 \mathrm{~W} \mathrm{~m}^{-2}$ are close to the effects presented in this study.

\subsection{Parameterisation of the CRE}

It would be beneficial for global climate analysis to apply the observed cloud radiative budgets and cloud radiative effects to other regions. To this end we developed a parameterisation of the CRE based on standard synoptical observations as they are available from e.g. the International Comprehensive Ocean-Atmosphere Data Set (ICOADS).

Due to the irrelevant meridional dependency of the CRE within the given latitudinal range (see Sect. 4.2), this new parameterisation applies to moderate, subtropical and tropical maritime climates only.

The parameterisation of the net cloud radiative effect $F_{\text {CRE_net }}$ is a function of the cloud cover $N$ and the solar zenith angle $\theta$. It consists of the LW and the SW term as follows:

$F_{\text {CRE_net }}(N, \theta)=F_{\text {CRE_LW }}(N)+F_{\text {CRE_SW }}(N, \theta)$.

The regression analysis was performed based on daytime measurements only due to availability of cloud cover information. Figure 4 shows the surface LW CRE as a function of the cloud cover. Cloud bottom height information was not available for all cruises and is rather uncertain from human observations. SST was also considered in our analysis, but no significant dependency was found (not shown here). During nighttime the observed LW CRE covers the same range (not shown here). The linear regression function for the LW cloud radiative effect $F_{\text {CRE_LW }}$ provided a relative explained variance with 0.810 :

$F_{\text {CRE_LW }}(N)=53.595 N, \quad N \in[0,1]$ 


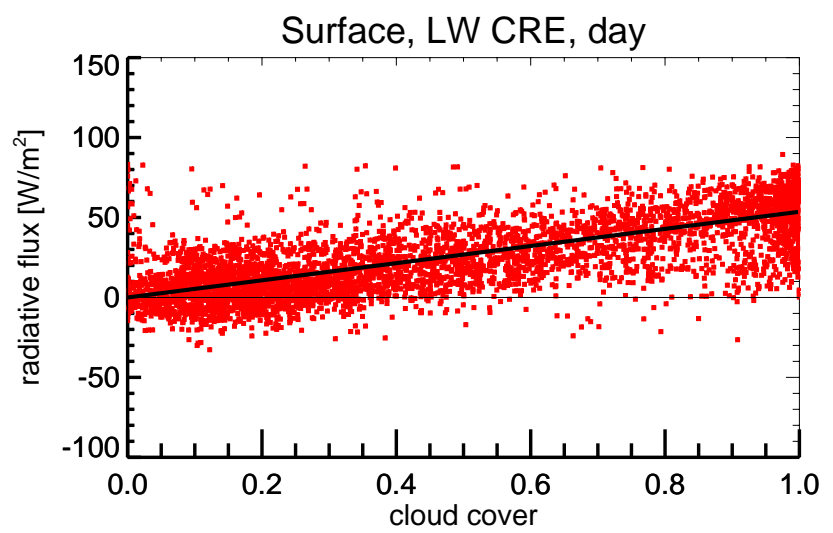

Fig. 4. Surface LW CRE as a function of daytime cloud cover. The black curve displays the linear regression function.

and is displayed in Fig. 4 in black colour. It features the ability to reproduce the full range of mean LW CREs (in $\mathrm{W} \mathrm{m}^{-2}$ ) from Table 3 if only cloud cover is available as input parameter. Its zero-crossing provides no LW effect for clear sky conditions.

In Fig. 5a the surface SW CRE as a function of cloud cover and the solar zenith angle on the basis of daytime observations is shown. By definition the SW CRE is zero at nighttime. If one of the parameters, either cloud cover or the cosine of the zenith angle amounts to zero, then the CRE is zero too. Small local outliers are due to exceptional weather scenarios with a corresponding impact on radiative properties, e.g. broken cloud events with radiation enhancements.

The following nonlinear cumulative extreme value function was generated to parameterise the surface SW cloud radiative effect $F_{\text {CRE_SW }}$ in $\mathrm{W} \mathrm{m}^{-2}$ :

$F_{\text {CRE_SW }}(N, \theta)=z_{0}+B \cdot \exp \left(-\exp \left(\frac{C-N}{D}\right)\right)+E \cdot \exp \left(-\exp \left(\frac{G-\cos \theta}{H}\right)\right)$

$+I \cdot \exp \left(-\exp \left(\frac{C-N}{D}\right)-\exp \left(\frac{G-\cos \theta}{H}\right)\right), \quad N \in[0,1]$

with the fitted constants:

$$
\begin{aligned}
& z_{0}=-46.2024 ; \\
& B=-2493.853 \\
& C=1.28125 ; \\
& D=0.53864 ; \\
& E=39.7732 ; \\
& G=0.35124 \\
& H=-0.42552 \\
& I=4434.38
\end{aligned}
$$

The relative explained variance amounts to 0.711 for a number of 5312 daytime measurements (10-min means) from the
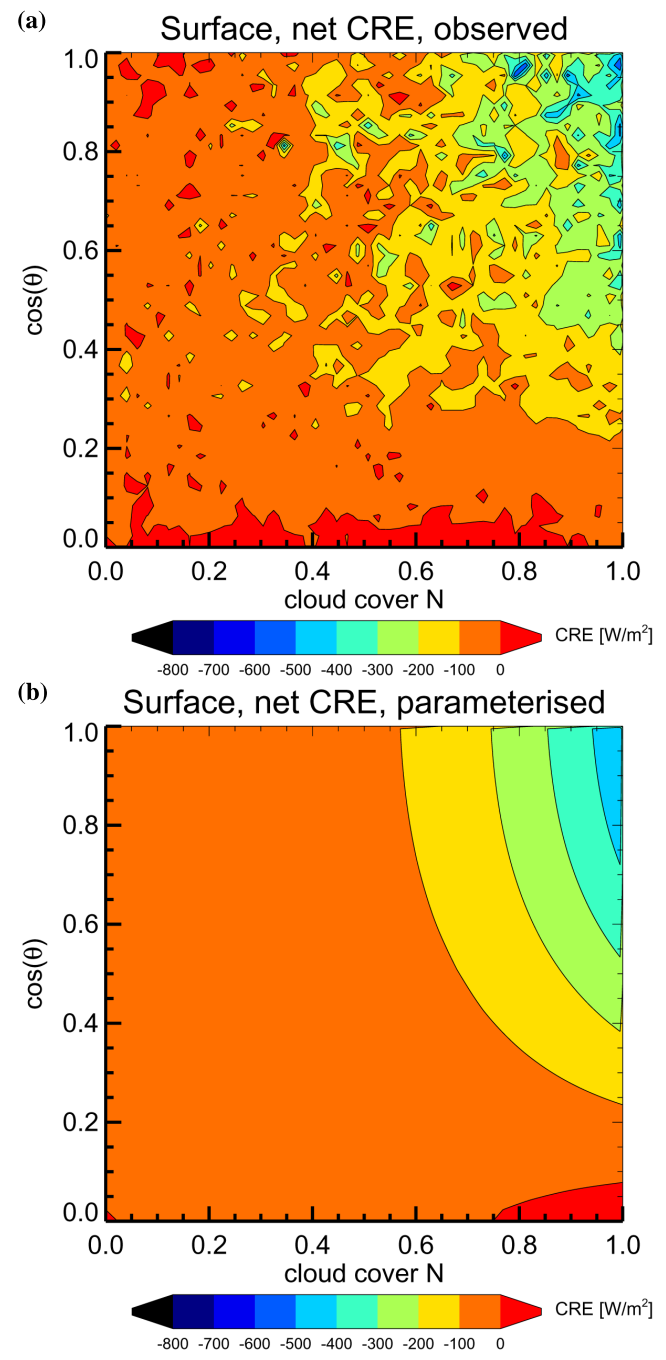

Fig. 5. Surface SW CRE as a function of daytime cloud cover and the solar zenith angle on the basis of calculations (based on measurements and clear sky parameterizations) in (a) and after fitting it onto a nonlinear extreme value function in (b).

five research cruises introduced in Sect. 2. This parameterisation is displayed as function of cloud cover and the solar zenith angle in Fig. 5b. It is not able to reproduce observed local maximal or minimal CREs originating from exceptional, optical thick clouds or radiation enhancements. The measured mean SW CREs for clear sky and cirrus (Table 3) is slightly out of the parameterisation range because of its close values to the limit.

A regression analysis for separate cloud types was not performed due to a low data density in case of rare cloud classes.

\subsection{Model simulation}

Radiative transfer simulations with the general circulation model (GCM) ECHAM5 (see Roeckner et al., 2003) have been performed to compare modelled radiative CREs to 


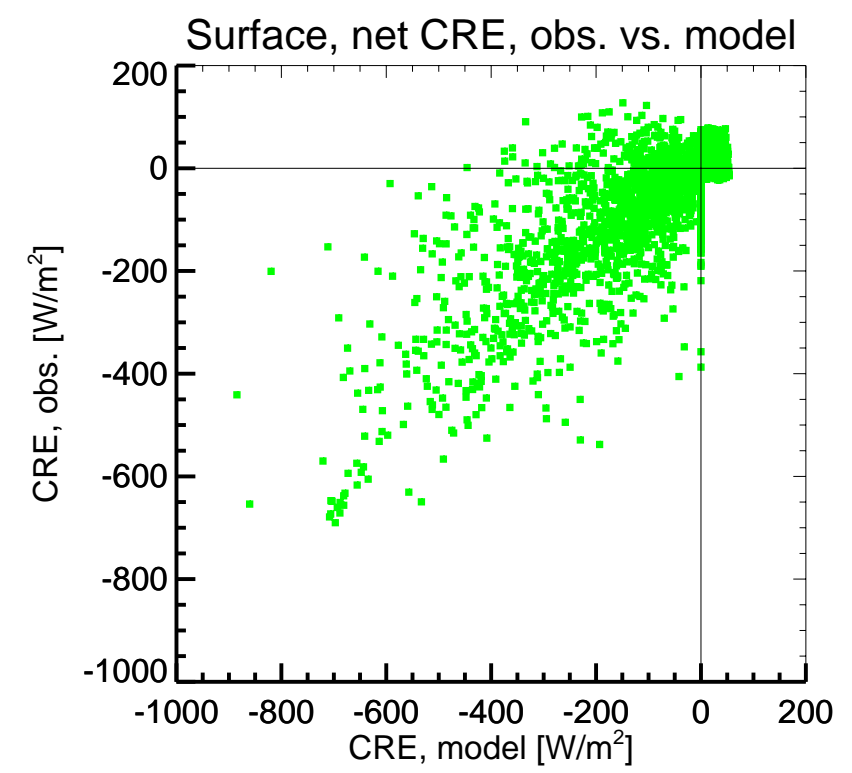

Fig. 6. Observed versus modelled surface net cloud radiative effect along the ship tracks of ANT-XXIV/1, ANT-XXIV/4 and ANT$\mathrm{XXV} / 5$.

observations. See Klocke et al. (2011) for characteristics and skills of the GCM. The aim is to test the radiative transfer scheme in ECHAM5 for a given state of the atmosphere. For this purpose the single column model (SCM) by Hanschmann et al. (2010) based on ECHAM5 was employed.

The SCM has been applied to measurements from the ship tracks of ANT-XXIV/1, ANT-XXIV/4 and ANT-XXV/5 with a T31 horizontal resolution with 19 vertical levels and a temporal resolution of $15 \mathrm{~min}$. The model input consists of observed temperature profiles, humidity profiles, liquid water path, integrated water vapour, surface pressure, total cloud cover and cloud bottom height. Additionally, ECHAMclimatologies for aerosols, gas concentrations and cloud droplet characteristics were used. Clouds have been implemented as a single homogeneous layer due to a lack of vertically resolved measurements. Dynamics and horizontal exchange processes were turned off, and the calculations have been performed for single time steps only. Detailed information is given in Hanschmann et al. (2010).

For the ECHAM-based surface CRE calculations, the LW and SW downward and upward fluxes as well as the clear sky fluxes have been taken from the model output. A scatterplot of the observed versus the modelled surface net CRE is shown in Fig. 6.

An over- or underestimation $\Delta F_{\mathrm{CRE}}$ of the modelled CRE $F_{\text {CRE_mod }}$ compared to the observed CRE $F_{\text {CRE }}$ (see Eq. 6) has been calculated for the LW, SW and net fluxes:

$\Delta F_{\mathrm{CRE}}=F_{\mathrm{CRE}}-F_{\mathrm{CRE} \_ \text {mod }}$.

The differences $\Delta F_{\mathrm{CRE}}$ of observed and modelled CREs in the LW, SW and net range are given in Table 4 for the entire
Table 4. Differences $\overline{\Delta F_{\mathrm{CRE}}}$ of observed minus modelled LW, SW and net surface cloud radiative effect in $\mathrm{W} \mathrm{m}^{-2}$ for the entire dataset and separated daytime cloud classes.

\begin{tabular}{lccc}
\hline \multicolumn{4}{c}{ Difference observed minus modelled surface CRE } \\
\hline & $\overline{\Delta F_{\text {CRE_LW }}}$ & $\overline{\Delta F_{\text {CRE_SW }}}$ & $\overline{\Delta F_{\text {CRE_net }}}$ \\
\cline { 2 - 3 } & \multicolumn{3}{c}{ All sky, full dataset } \\
\hline \multicolumn{4}{c}{18.1} \\
\hline Class (cloud type) & \multicolumn{3}{c}{ Daylight measurements } \\
\hline 1 (Cu) & 2.7 & 27.0 & 28.3 \\
2 (Ci, Cs) & 1.2 & 6.5 & 6.2 \\
$3(\mathrm{Cc}$, Ac) & 12.1 & 64.4 & 74.8 \\
$4(\mathrm{clear}$ sky) & -1.2 & 1.5 & 0.3 \\
$5(\mathrm{Sc})$ & 11.0 & 114.2 & 125.6 \\
$6(\mathrm{St}, \mathrm{As})$ & 25.4 & -45.1 & -21.4 \\
7 (Cb, Ns) & 21.2 & 94.5 & 118.7 \\
\hline
\end{tabular}

dataset and separated into the daytime cloud classes. An underestimation of the modelled CRE is defined with negative sign; an overestimation comes with positive sign. The standard deviation of the modelled CRE for each cloud type is within the range of the measured results.

In general the SCM is not able to simulate SW radiative enhancements due to broken clouds. In our experiments a simulation of short-term fluctuations of radiative fluxes is not possible due to the model temporal resolution and the timeaveraged model input (10-min averages).

The modelled net CRE is dominated by the SW fluxes. On average the SCM net CRE overestimates the observed CRE by $17 \mathrm{~W} \mathrm{~m}^{-2}$. Convective clouds lead to large overestimations of the modelled CREs (cloud classes 1, 3, 5, 7). The surface solar effects of convective clouds, especially stratocumulus, show a large overestimation of up to $114 \mathrm{~W} \mathrm{~m}^{-2}$. With respect to the large absolute SW CRE of stratus clouds, its underestimation of $-45 \mathrm{~W} \mathrm{~m}^{-2}$ is fairly close to the observed CRE. For the clear sky conditions, small CREs were calculated due to the sky imagers misclassification (presence of minor cloud cover).

Due to the different accuracies of the modelled CREs for different cloud types, ECHAM5 simulations may lead to large regional errors in energy budgets depending on the dominant cloud type. The different convection parameterisation by Wagner and Graf (2010) could improve the simulated CREs for cumulus, stratocumulus, altocumulus and cumulonimbus. This method simulates each cloud type using a one-dimensional Lagrangian entraining parcel model, which includes mixed phase microphysics and provides information about cloud height and cloud coverage. Further improvements of the modelled CRE can be expected if the CREs for a number of independent atmospheric columns are averaged in order to account for horizontal cloud variability (see Räisänen et al., 2007). Additionally, an improved remote 
sensing of the vertical structure of clouds, e.g. by means of a radar system, would lead to a higher quality of the input data and would allow a more exact parameterisation of subgrid convective clouds.

\section{Conclusions}

In this study we present a detailed quantification of surface cloud radiative effects for the LW, SW and total spectral range. Special attention was given to different cloud classes and their impact on the radiative fluxes. The meridional shipbased measurements of the surface radiative fluxes and atmospheric properties provided a unique dataset to capture cloud effects in different climate zones.

The surface net radiative fluxes and the CREs show no significant meridional dependency within the latitudinal range under investigation. The net radiative flux and the CRE are dominated by the SW radiation. In the SW range clouds lead to a mean cooling effect, but broken clouds can cause shortterm positive effects due to radiation enhancements. Due to the tropical impact on cloud occurrence and evolution, a diurnal cycle of cloud cover was found for cumulus, altocumulus and clear skies with a corresponding impact on the CREs. The mean net CRE amounts to $-33 \mathrm{~W} \mathrm{~m}^{-2}$ and is close to the CRE for the tropical Pacific with $-40 \mathrm{~W} \mathrm{~m}^{-2}$ by Fairall et al. (2008).

On the basis of the observed mean CRE, an all-cloud parameterisation was introduced to estimate the $\mathrm{LW}, \mathrm{SW}$ and net CRE using cloud cover and solar zenith angle as input values. A future intensification of observations will provide robust datasets for each cloud class and allow for cloud-type specific parameterisations of CREs.

The CREs from the ECHAM5 SCM have shown a stronger cooling by $17 \mathrm{~W} \mathrm{~m}^{-2}$ mostly caused by an overestimated SW impact of convective clouds. An improvement of convection parameterisations may improve the simulation of subgrid processes. Radiative fluxes of clear sky and stratus clouds are modelled close to observations.

Both the observations on meridional expeditions and the data analysis will continue and will lead to a more robust database of marine cloud radiative effects for climate analysis and climate model evaluation. The remote sensing by means of cloud radar system will provide the vertical structure and horizontal variability, which in turn improves our ability to parameterise cloud radiative effects in terms of physical cloud properties. Together with satellite-based top-of-atmosphere radiative fluxes, the atmospheric radiative fluxes can be determined (see Kalisch, 2011).

Acknowledgements. We kindly acknowledge the support in various SCM input-output conversions and model runs by Timo Hanschmann from the Leibniz-Institute for Tropospheric Research (IfT). We would like to thank Anna Heinle from the Department of Computer Science at the Kiel University for the cloud classifier algorithm. And many thanks to the Alfred Wegener Institute for Polar and Marine Research (AWI) for providing the opportunity to join several research cruises across the Atlantic Ocean on RV Polarstern, especially the expeditions ANT-XXIII/10, ANT-XXIV/1, ANT-XXIV/4, ANT-XXV/5 and ANT-XXVI/1.

Edited by: P. Stammes

\section{References}

Bharmal, N. A., Slingo, A., Robinson, G. J., and Settle, J. J.: Simulation of surface and top of atmosphere thermal fluxes and radiances from the radiative atmospheric divergence using the ARM Mobile Facility, GERB data, and AMMA Stations experiment, J. Geophys. Res., 114, D00E07, doi:10.1029/2008JD010504, 2009.

Chen, T., Rossow, W. B., and Zhang, Y.: Radiative effects of cloudtype variations, J. Climate, 13, 264-286, 2000.

Dera, J.: Marine Physics, PWN - Polish Scientific Publishers, Warszawa, 1992.

Duda, R. O. and Hart, P. E.: Pattern classification, John Wiley and Sons, 680 pp., 2001.

Dupont, J.-C. and Haeffelin, M.: Observed instantaneous cirrus radiative effect on surface-level shortwave and longwave irradiances, J. Geophys. Res., 113, D21202, doi:10.1029/2008JD009838, 2008.

El Naggar, S. and Macke, A. E.: The Expedition of the Research Vessel "Polarstern" to the Antarctic in 2009 (ANT-XXVI/1), in: Berichte zur Polar- und Meeresforschung - Reports on Polar and Marine Research edited by: El Naggar, S. and Macke, A., 614, Alfred-Wegener-Institut, Bremerhaven, 75 pp., 2010.

Eucken, A.: Landolt-Börnstein: 3. Band, Astronomie und Geophysik, Landolt-Börnstein: Zahlenwerte und Funktionen aus Physik, Chemie, Astronomie, Geophysik und Technik, 6th Edn., 1952.

Fairall, C. W., Uttal, T., Hazen, D., Hare, J., Cronin, M. F., Bond, N., and Veron, D. E.: Observations of Cloud, Radiation, and Surface Forcing in the Equatorial Eastern Pacific, J. Climate, 21, 655673, 2008.

Feister, U. and Shields, J.: Cloud and radiance measurements with the VIS/NIR Daylight Whole Sky Imager at Lindenberg (Germany), Meteorol. Z., 14, 627-639, 2005.

Greenwald, T. J., Lee, Y.-K., Otkin, J. A., and L'Ecuyer, T.: Evaluation of midlatitude clouds in a large-scale high-resolution simulation using CloudSat observations, J. Geophys. Res., 115, D19203, doi:10.1029/2009JD013552, 2010.

Hanschmann, T., Macke, A., Roebeling, R., and Deneke, H.: Application of CM-SAF cloud and radiation products to verify surface cloud radiative effects in climate models over ocean, Visiting Scientists Report within the SAF on Climate Monitoring of EUMETSAT, 66 pp., 2010.

Heinle, A., Macke, A., and Srivastav, A.: Automatic cloud classification of whole sky images, Atmos. Meas. Tech., 3, 557-567, doi:10.5194/amt-3-557-2010, 2010.

Idso, S. B. and Jackson, R. D.: Thermal Radiation from the Atmosphere, J. Geophys. Res., 74, 5397-5403, 1969.

Jiménez, J. I., Alados-Arboledas, L., Castro-Diez, Y., and Ballester, G.: On the estimation of long-wave radiation flux from clear skies, Theor. Appl. Climatol., 38, 37-42, 1987. 
Jin, Z., Charlock, T., and Rutledge, K.: Analysis of Broadband Solar Radiation and Albedo over the Ocean Surface at COVE, J. Atmos. Ocean. Tech., 19, 1585-1601, 2002.

Kalisch, J.: Der Einfluss von Wolken auf den Strahlungsantrieb der Erde, PhD Thesis, Leibniz Institute of Marine Sciences at Kiel University (IFM-GEOMAR), Kiel, Germany, 147 pp., 2011.

Kalisch, J. and Macke, A.: Estimation of the total cloud cover with high temporal resolution and parametrization of short-term fluctuations of sea surface insolation, Meteorol. Z., 17, 603-611, 2008.

Kasten, F. and Czeplak, G.: Solar and terrestrial radiation dependent on the amount and type of cloud, Sol. Energy, 24, 177-189, 1980.

Kent, E. C. and Berry, D. I.: Quantifying random measurement errors in voluntary observing ship meteorological observations, Int. J. Climatol., 25, 843-852, 2005.

Kent, E. C., Taylor, P. K., Truscott, B. S., and Hopkins, J. A.: The accuracy of Voluntary Observing Ship's Meteorological Observations, J. Atmos. Ocean. Tech., 10, 591-608, 1993.

Kiehl, J. T. and Trenberth, K. E.: Earth's annual global mean energy budget, B. Am. Meteorol. Soc., 78, 197-208, 1997.

Kipp \& Zonen: Instruction Manual CG 4. - Manual Version: 0304, Kipp \& Zonen B.V., Delftechpark 36, 2628 Delft, Niederlande, 2001.

Kipp \& Zonen: Instruction Manual CM 21. - Manual Version: 0904, Kipp \& Zonen B.V., Delftechpark 36, 2628 Delft, Niederlande, 2004.

Klocke, D., Pincus, R., and Quaas, J.: On contraining estimates of climate sensitivity with present-day observations through model weighting, J. Climate, 24, 6092-6099, 2011.

König-Langlo, G., Loose, B., and Bräuer, B.: 25 Years of Polarstern Meteorology, Vol. 4 of WDC-Mare Reports, Alfred-WegenerInstitut, Bremerhaven, 137 pp., 2006.

Kopp, G. and Lean, J.: A new, lower value of total solar irradiance: Evidence and climate significance, Geophys. Res. Lett., 38, L01706, doi:10.1029/2010GL045777, 2011.

Kopp, G., Lawrence, G., and Rottman, G.: The Total Irradiance Monitor (TIM): science results, Sol. Phys., 230, 129-139, 2005.

Lean, J., Rottman, G., Harder, J., and Kopp, G.: SORCE contributions to new understanding of global change and solar variability, Sol. Phys., 230, 27-53, 2005.

Li, J., Scinocca, J., Lazare, M., McFarlane, N., von Salzen, K., and Solheim, L.: Ocean Surface Albedo and Its Impact on Radiation Balance in Climate Models, J. Climate, 19, 6314-6333, 2006.

Long, C. N. and DeLuisi, J. J.: Development of an Automated Hemispheric Sky Imager for Cloud Fraction Retrievels, 1116 January 1998, Phoenix, Arizona, 1998.

Macke, A. E.: The Expedition ANTARKTIS-XXIII/10 of the Research Vessel "Polarstern" in 2007, in: Berichte zur Polar- und Meeresforschung - Reports on Polar and Marine Research, edited by: Macke, A., 575, Alfred-Wegener-Institut, Bremerhaven, 33 pp., 2008.

Macke, A. E.: The Expedition of the Research Vessel "Polarstern" to the Antarctic in 2008 (ANT-XXIV/4), in: Berichte zur Polarund Meeresforschung - Reports on Polar and Marine Research, edited by: Macke, A., 591, Alfred-Wegener-Institut, Bremerhaven, 65 pp., 2009.

Macke, A., Kalisch, J., and Hollmann, R.: Validation of downward surface radiation derived from MSG data by in-situ observations over the Atlantic ocean, Meteorol. Z., 19, 155-167, 2010a.
Macke, A., Kalisch, J., Zoll, Y., and Bumke, K.: Radiative effects of the cloudy atmosphere from ground and satellite based observations, EPJ Web of Conferences, 9, 83-94, 2010b.

Marra, J.: Effect of short-term variations in light intensity on photosynthesis of a marine phytoplankter. A laboratory simulation study, Mar. Biol., 46, 203-208, 1978.

Miller, R. L., Slingo, A., Barnard, J. C., and Kassianov, E.: Seasonal contrast in the surface energy balance of the Sahel, J. Geophys. Res., 114, D00E05, doi:10.1029/2008JD010521, 2009.

Pallé, E. and Butler, C. J.: Comparison of sunshine records and synoptic cloud observations: A case study for Ireland, Phys. Chem. Earth, 27, 405-414, 2002.

Räisänen, P., Järvenoja, S., Järvinen, H., Giorgetta, M., Roeckner, E., Jylhä, K., and Ruosteenoja, K.: Tests of Monte Carlo Independent Column Approximation in the ECHAM5 Atmospheric GCM, J. Climate, 20, 4995-5011, 2007.

Ramanathan, V., Cess, R. D., Harrison, E. F., Minnis, P., Barkstrom, B. R., Ahmad, E., and Hartmann, D.: Cloud-Radiative Forcing and Climate: Results from the Earth Radiation Budget Experiment, Science, 243, 57-63, 1989.

Roeckner, E., Bäuml, G., Bonaventura, L., Brokopf, R., Esch, M., Giorgetta, M., Hagemann, S., Kirchner, I., Kornblueh, L., Manzini, E., Rhodin, A., Schlese, U., Schulzweida, U., and Tomkins, A.: The atmospheric general circulation model ECHAM5: Part I: Model description, MPI Rep. 349, MaxPlanck-Institut für Meteorologie, Hamburg, Germany, 127 pp., 2003.

Rose, T., Crewell, S., Löhnert, U., and Simmer, C.: A network suitable microwave radiometer for operational monitoring of the cloudy atmosphere, Atmos. Res., 75, 183-200, 2005.

Rossow, W. B. and Zhang, Y.-C.: Calculation of surface and top of atmosphere radiative fluxes from physical quantities based on ISCCP data sets 2. Validation and first results, J. Geophys. Res., 100, 1167-1197, 1995.

Rottman, G.: Measurement of total and spectral solar irradiance, Space Sci. Rev., 125, 39-51, 2006.

Schade, N. H., Macke, A., Sandmann, H., and Stick, C.: Enhanced solar global irradiance during cloudy sky conditions, Meteorol. Z., 16, 295-303, 2007.

Schiel, S. E.: The Expedition of the Research Vessel "Polarstern" to the Antarctic in 2007 (ANT-XXIV/1), in: Berichte zur Polarund Meeresforschung - Reports on Polar and Marine Research, edited by: Schiel, S., 592, Alfred-Wegener-Institut, Bremerhaven, 112 pp., 2009.

Schluessel, P., Emery, W. J., Grassl, H., and Mammen, T.: On the Bulk-Skin Temperature Difference and Its Impact on Satellite Remote Sensing of Sea Surface Temperature, J. Geophys. Res., 95, 13341-13356, 1990.

Slingo, A., White, H. E., Bharmal, N. A., and Robinson, G. J.: Overview of observations from the RADAGAST experiment in Niamey, Niger: 2. Radiative fluxes and divergences, J. Geophys. Res., 114, D00E04, doi:10.1029/2008JD010497, 2009.

Sui, C.-H., Lau, K.-M., Takayabu, Y. N., and Short, D. A.: Diurnal Variations in Tropical Oceanic Cumulus Convection during TOGA COARE, J. Atmos. Sci., 54, 639-655, 1997.

Trenberth, K. E., Fasullo, J. T., and Kiehl, J. T.: Earth's global energy budget, B. Am. Meteorol. Soc., 90, 311-323, 2009.

Wagner, T. M. and Graf, H. F.: An Ensemble Cumulus Convection Parameterization with Explicit Cloud Treatment, J. Atmos. Sci., 
67, 3854-3869, doi:10.1175/2010JAS3485.1, 2010.

Walsh, P. and Legendre, L.: Photosynthesis of natural phytoplankton under high frequency light fluctuations simulating those induced by sea surface waves, Limnol. Oceanogr., 28, 688-697, 1983.

Webster, P. J., Clayson, C. A., and Curry, J. A.: Clouds, radiation and the diurnal cycle of sea surface temperature in the tropical western Pacific, J. Climate, 9, 1712-1730, 1996.

Zenk, W. and El Naggar, S. E. (Eds.): The Expedition of the Research Vessel "Polarstern" to the Antarctic in 2009 (ANTXXV/5), in: Berichte zur Polar- und Meeresforschung - Reports on Polar and Marine Research, 603, Alfred-Wegener-Institut, Bremerhaven, 59 pp., 2010.
Zhang, Y., Rossow, W. B., Lacis, A. A., Oinas, V., and Mishchenko, M. I.: Calculation of radiative fluxes from the surface to the top of atmosphere based on ISCCP and other global data sets: Refinements of the radiative transfer model and the input data, J. Atmos. Geophys. Res., 109, 591-608, doi:10.1029/2003JD004457, 2004.

Zillman, J.: A study of some aspects of the radiation and heat budgets of the Southern Hemisphere oceans, in: Meteor. Stud., No. 26, Bureau of Meteorology, Canberra, Australia, 1972, 526 pp., 1972. 